\title{
Laboratory Researches Regarding Wear of the Composite Materials for Making Brake Shoes
}

\author{
ERIKA ARDELEAN ${ }^{2 *}$, ANA SOCALICI ${ }^{1}$, LIVIU PASCU ${ }^{2}$, VASILE PUTAN ${ }^{1}$, TEODOR HEPUT $^{1}$ \\ IUnivesity Politehnica Timisoara, Faculty Engineering of Hunedoara, 5 Revolutiei Str., 331128, Hunedoara, Romania \\ ${ }^{2}$ Technical College of Railway Transportation Anghel Saligny, 137 National Road, 335900, Simeria, Romania
}

The paper presents the results of the experiments on obtaining a composite material to be used in manufacturing brake shoes for the rolling stock. The aim was to replace the classical material used at present for the manufacturing of brake shoes: cast iron with a specially designed composite material. Six recipes have been tested and compared to a standard sample made of phosphorous cast iron. The wear trials carried out in laboratory conditions on the experimental test rods have led to results that entitle further experiments that implies the manufacturing of brake shoes made of the composite material in question.

Keywords: organic materials, composite, noise, wear, brake shoes

The European Commission has taken a series of steps and elaborated technical specifications for interoperability related to railroad noise [1, 2], introducing limitations for the rolling stock used in the European Union. These limitations apply to the new or refurbished rolling stock, which has to be equipped with silent breaking pads, meant to cut down noise. The most economical means of achieving that is by replacing the breaking system, as replacing the whole vehicle fleet is extremely expensive. It is recommended to replace the cast iron breaking pads by pads made of composite materials.

They are efficient in noise reduction (by $10 \mathrm{~dB}$, which means $50 \%$ of the noise produced by the cast iron brake shoes) [2]. This post-refurbishing should be done for all the European freight carriages which run over $10000 \mathrm{~km}$ annually and whose remaining life span is at least 5 years.

The profile industry developed several types of brake shoes made of composite materials in order to replace the conventional, cast iron pads, which represent the main cause of rail and wheel roughness [2-4]. K brake shoes are made of organic composite materials and have braking characteristics that differ from those of the traditional pads. They are highly efficient in terms of noise reduction, the technology has been tested on new carriages, but it supposes high refurbishing expenses. The LL brake shoes need just minor adjustments of the breaking system, they have breaking characteristics almost similar to the cast iron pads and are made of either organic or sintered metal composite materials. They offer noise reduction similar to the $\mathrm{K}$ pads and are particularly meant for refurbishing. Refurbishing leads to investment costs ranging from 200 to 700 million euro (LL pads) or 1,0-1,8billion euro (K pads) plus extra maintenance costs worth of 200-400 million euro (added up until 2025, for both technologies) [4-11]. The European Commission [4] recommends the obtaining of high quality composite materials for brake shoes in order to significantly cut down both costs and noise.

\section{Experimental part}

The paper presents the laboratory experiments made to obtain composite materials meant for the brake shoes to be used by train engines or carriages, characterization of the samples obtained and interpretation of the results.

For the laboratory trials of the composite materials meant to be used to manufacturing brake shoes, the following test rods have been established:

- a standard sample test rod made of $P 10$ phosphorous cast iron (Ss);

- 6 test rods made of composite material (R1-R6).

The standard sample test rod was made of $P 10$ phosphorous cast iron $[12,13]$, a material that is used in practice for the conventional brake shoes. The characteristics of this standard sample have been taken as reference for the composite material. Six experimental tests rods were made for the composite material, using the following components: Novolac, Hexamethylenetetramine, sulphur, Carbon fibre, graphite, aluminium, brass and rubber. Figure 1 presents the component recipes.

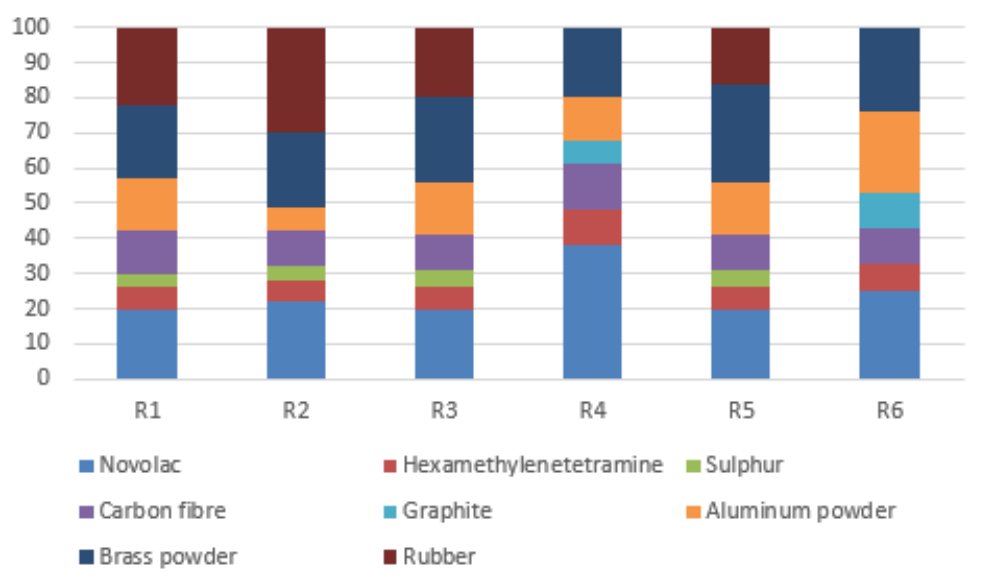

Fig.1. The component recipes [\%] used in laboratory experiments

* email: erika.ardelean@fih.upt.ro 
The (cylinder - type) test rods having a diameter of $ø 14 \mathrm{~mm}$ and a height of about $30 \mathrm{~mm}$, were cast in metallic moulds. The quantities of elements in each recipe were determined by calculation and by preliminary trials. Part of the phenolic resin (about 70\%) went through a heating process to $70^{\circ} \mathrm{C}$, then the other components, including the rest of solid phenolic resin (30\%), was incorporated in it, one at a time. The mould was filled with this mixture and it was periodically pressed [7]. A homogenous distribution of the components is necessary for obtaining a high quality composite material.

The composite material in the mould was cold pressed in a 2000MPa hydraulic press. The sample rod was sintered before being removed from the mould. The optimal sintered temperature, established by trials, was $200^{\circ} \mathrm{C}$. From each recipe three test rods had been produced (fig.2).

$$
u=m_{0}-m_{f},[\mathrm{~g}]
$$

where:

$m_{0}$ is the mass of the test rod before the trial, [g];

$m_{f}$ - the mass of the test rod after the trial, [g].

Relation (2) determines the trajectory mass wear rate:

$$
U_{p}=\frac{u}{L_{u}}=\frac{m_{0}-m_{f}}{L_{u}},[\mathrm{~g} / \mathrm{m}]
$$

where $L_{u}$ is the wear trajectory, $[\mathrm{m}]$.

Comparing the test rod mass wear of the composite material $\left(u_{c}\right)$ to the mass wear of the sample cast iron test $\operatorname{rod}\left(u_{f}\right)$, the calculated relative wear is, according to relation (3):

$$
u_{r}=\frac{u_{c}}{u_{f}}
$$

Table 1

DIMENSIONAL CHARACTE-RISTICS OF THE SAMPLES

\begin{tabular}{|c|c|c|c|c|}
\hline $\begin{array}{c}\text { No. } \\
\text { sample }\end{array}$ & $\begin{array}{c}\text { Initial mass } \\
\text { sample } \\
m b \\
{[\mathrm{~g}]}\end{array}$ & $\begin{array}{c}\text { Final mass } \\
\text { sample } \\
m_{f} \\
{[\mathrm{~g}]}\end{array}$ & $\begin{array}{c}\text { Initial height } \\
\text { sample } \\
l_{i} \\
{[\mathrm{~mm}]}\end{array}$ & $\begin{array}{c}\text { Final height } \\
\text { sample } \\
l_{f} \\
{[\mathrm{~mm}]}\end{array}$ \\
\hline Ss & 30.531 & 30.379 & 32.0 & 31.95 \\
\hline R1 & 4.825 & 3.535 & 32.2 & 23.1 \\
\hline R2 & 4.752 & 3.331 & 31.7 & 23.1 \\
\hline R3 & 3.919 & 2.600 & 31.6 & 21.1 \\
\hline R4 & 6.044 & 5.295 & 31.7 & 27.0 \\
\hline R5 & 7.670 & 5.829 & 29.9 & 23.4 \\
\hline R6 & 7.221 & 5.247 & 30.8 & 22.5 \\
\hline
\end{tabular}

Table 2

THE RESULTING DATA FOR THE EXPERIMENTAL SAMPLES

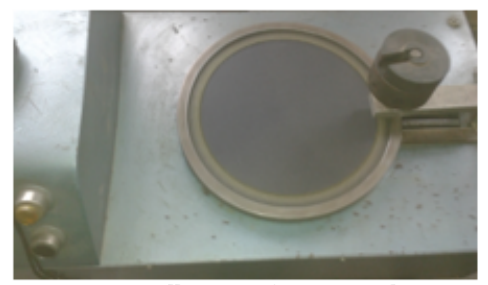

Fig. 3. Installation of testing abrasive wear with abrasive disc

\begin{tabular}{|c|c|c|c|c|c|c|}
\hline $\begin{array}{c}\text { No. } \\
\text { sample }\end{array}$ & $\begin{array}{c}\text { Mass } \\
\text { wear } \\
u, \\
{[\mathrm{~g}]}\end{array}$ & $\begin{array}{c}\text { Mass wear rate } \\
\text { over the length } \\
\text { covered } \\
U p, \\
{[\mathrm{~g} / \mathrm{m}]}\end{array}$ & $\begin{array}{c}\text { Relative } \\
\text { mass wear, } \\
{[\%]}\end{array}$ & $\begin{array}{c}\text { Reducing } \\
\text { absolute } \\
\text { height, } \\
{[\mathrm{mm}]}\end{array}$ & $\begin{array}{c}\text { Reducing } \\
\text { relative } \\
\text { height, } \\
{[\%]}\end{array}$ & $\begin{array}{c}\text { Relative } \\
\text { wear, }\end{array}$ \\
\hline Ss & 0.152 & 0.00217 & 0.498 & 0.05 & 0.156 & - \\
\hline R1 & 1.290 & 0.01842 & 26.74 & 9.10 & 27.91 & 8.48 \\
\hline R2 & 1.421 & 0.02028 & 29.88 & 8.60 & 27.12 & 9.34 \\
\hline R3 & 1.319 & 0.01884 & 34.44 & 10.5 & 23.21 & 8.67 \\
\hline R4 & 0.749 & 0.01070 & 12.47 & 4.1 & 12.95 & 4.92 \\
\hline R5 & 1.841 & 0.02630 & 24.01 & 6.5 & 21.82 & 12.11 \\
\hline R6 & 1.974 & 0.02820 & 27.33 & 8.3 & 26.93 & 12.98 \\
\hline
\end{tabular}

The resulting test rods were subjective to a wear test on an installation of testing abrasive wear with abrasive disc (fig.3).

The trials were performed according to STAS 9639-81 and consists in pressing the test rod made of the material under examination against a rotating disc, in order to determine certain abrasive wear characteristics [10]. HE 16 polishing silicon carbide paper was used as abrasive, which is supplied as $\varnothing 310 \mathrm{~mm}$ diameter discs. The length of the wear spiral trajectory results from the combination of the two movements (rotation and advance) and has the value of $70 \mathrm{~m}$ during $7.08 \mathrm{~min}$. The assessment of the behaviour of the test rods has been done by the gravimetric method (mass loss). Table 1 gives the dimensional characteristics of the test rods.

For each test rod, the mass wear, trajectory mass wear rate and the relative wear were determined.

Relation (1) determines mass wear u:
Table 2 shows the resulting data for the experimental samples.

\section{Results and discussions}

The analysis of the data shows that the lowest mass wear of the composite material is that of sample rod R4. As compared to the cast iron standard sample rod, the sample rods made of composite material have a higher mass wear, but their behaviour is similar to that of the composite materials used at present in manufacturing brake shoes $[7,8]$. Experimental sample rod R6 showed the highest wear.

Mass wear has also been analysed in terms of the composition of the recipes (respectively the main components). The aim was to find the optimal composition of the chosen composite, so that it would show the slightest mass wear. Thus, figure 4 shows the variation of the mass wear according to the content of Novolac; the composite 
having a content of Novolac between $35-40 \%$ shows the highest wear resistance.

The analysis of the influence of the content of Hexamethylenetetramine (used to turn the thermoplastic resin into a thermo-rigid one), has led to the conclusion that a content of $10 \%$ has a positive influence upon the decrease of wear resistance (fig. 5).

It was used Carbon fibre in order to reinforce the composite, and graphite to reduce the friction coefficient powder. Mass wear was cut down to a minimum for an interval within 17-19.5\% Carbon fibre and graphite (fig. 6).

Figure 7 shows the variation of the relative height reduction according to the content of aluminium powder and brass powder.

\section{Conclusions}

The paper presents the results of the experiments on obtaining composite materials meant for the manufacturing of rolling stock brake shoes.

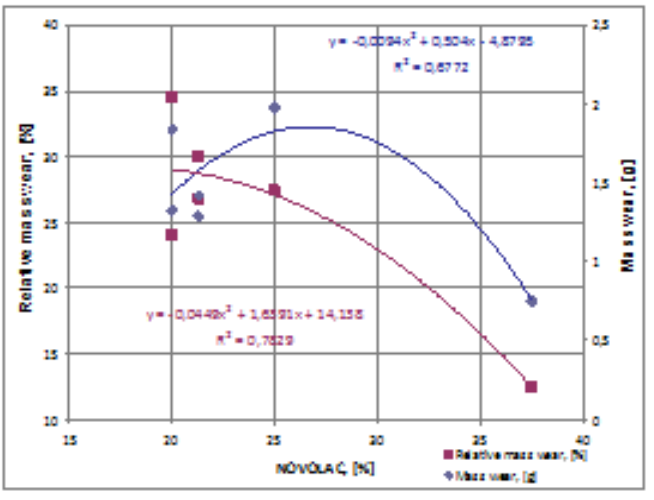

a.

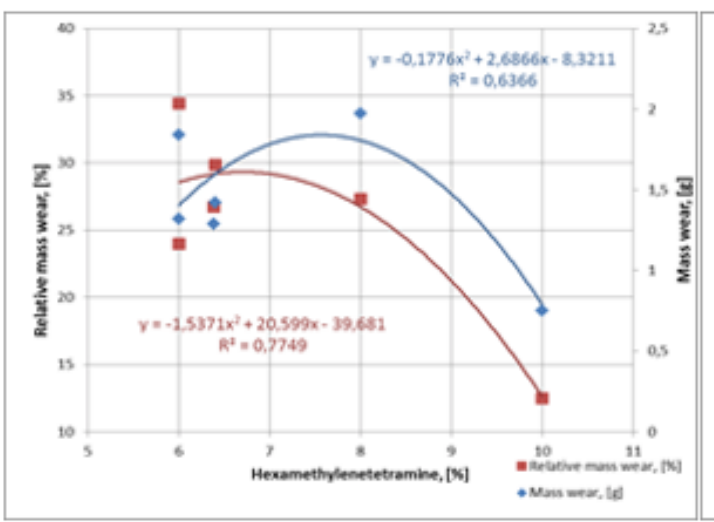

a.

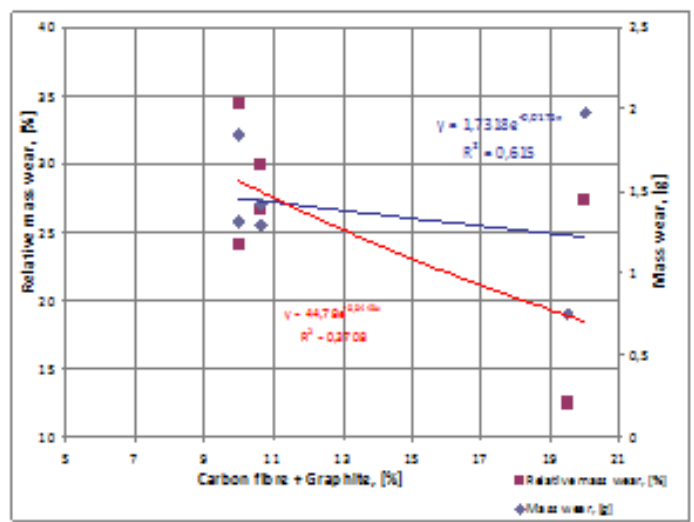

a.

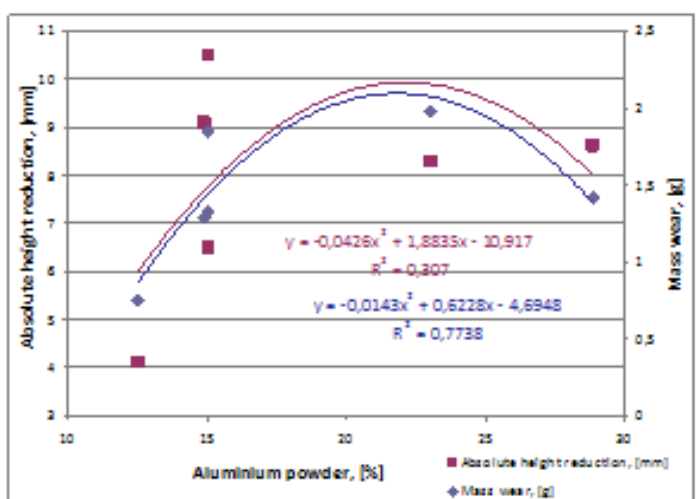

a.

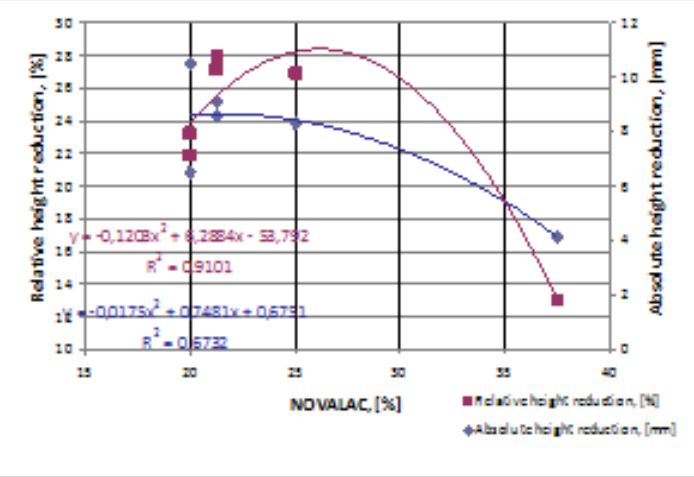

b.

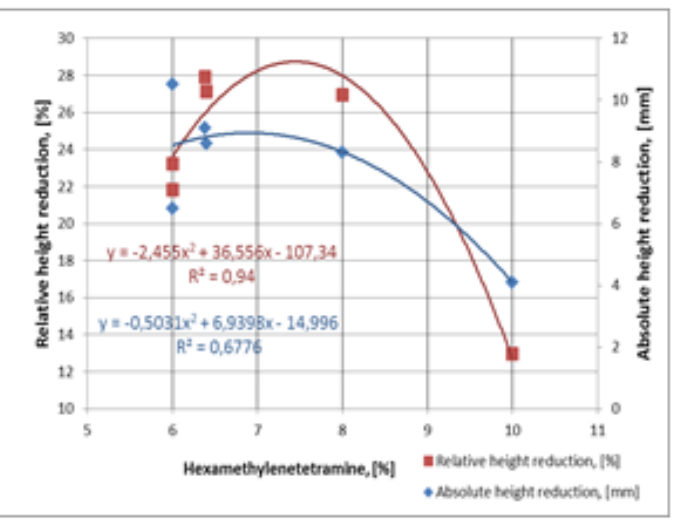

b.

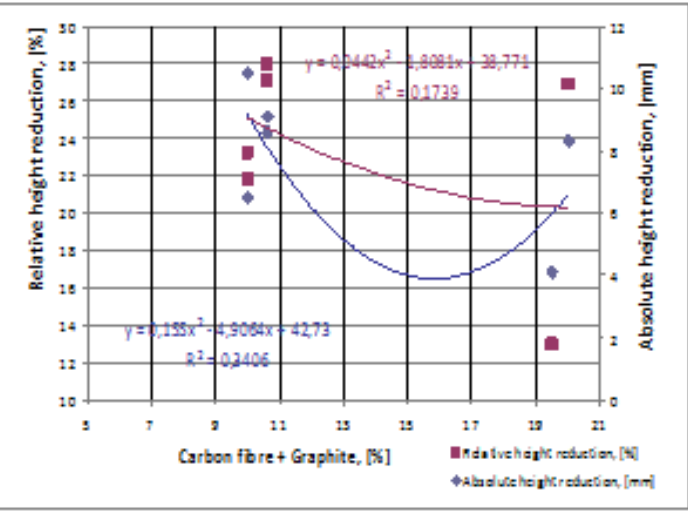

b.

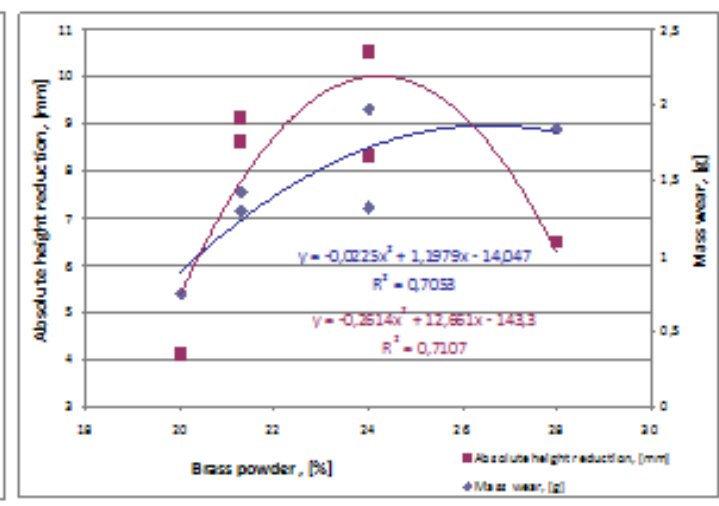

b.
Fig. 4. Variation of relative mass wear (a) and relative height reduction (b) according to the Novalac content

Fig. 5. Variation of relative mass wear (a) and relative height reduction (b) according to the Hexametyltetramine content

Fig. 6. Variation of relative mass wear (a) and relative height reduction (b) according to the Carbon fibre and graphite content

Fig. 7. Variation of relative height reduction and according to the aluminium powder (a) and brass powder content (b) 
The analysis of the experiments and their results leads to the following conclusions:

- the test rod with the highest resistance to abrasive wear is R4; this could be explained by the proportion of components and of the manufacturing technology (the proportion of the components Novolac, Hexamethylenetetramine, carbon fibre and graphite ranged towards the maximal limits);

- the resistance to abrasive wear is satisfactory in case of test rods R1, R2 and R3, due to the fact that the manufacturing technology is the same and the structure of the components varies within narrow limits;

- test rod R6 has the highest resistance to abrasive wear, and for that reason ithas further been studied, in an attempt to improve its behaviour under abrasive wear.

Considering the results, the best behaviour to wear of the experimental composite materials, was the one of test rods produced according to recipe R4. Experiments will continue in order to finalize the recipe and the manufacturing technology, in order to obtain the best values for the indices under consideration.

\section{References}

1. *** EU Commission Decision 2006/66/EC concerning the technical specification for interoperability relating to the 'material stock - noise of the conventional rail system.

2. Directive 2002/49/CE, JO L 189, 18.7.2002, p. 12.

3. ENACHESCU, G., STEFANESCU, M., Mat. Plast, 53, no.2, 2016, p.198
4. Commission of European Communities, Measures to reduce rail noise from the existing fleet, COM 432, Bruxelles, 2008.

5. NEHARKAR, P., PATIL, R.J.,SONAWANE, P.R., Study of friction and wear for optimization of disc break material for reduction of brake sound, International J ournal of Research in Aeronautical and Mechanical Engineering, 2 no. 6, 2014, p.137.

6. XEPAPADAKI, A., PAPANICOLAOU, G., KERAMIDAS, P., JIGA, G., Mat. Plast, 47, no.2, 2010, p.153

7. PASCU, L., PhD thesis, Researches on Improving the Quality of Brake Shoes Meant for Use with the Rolling Stock, Politehnica Timisoara, Romania, 2015

8. OERTLI, J., Railway Noise Control In Europe, Current Status, International workshop on railway Noise, Uddevalla Sweden, 2013, p.1.

9. TUDOR, D., PETRESCU, H., HADAR, A., ROSU, D., Mat. Plast, 49, no.2, 2012, p.123

10. STAS 9639 - 81, Testing of metals. Trying to wear on rotating disc sanding paper

11. COCARD, M., MARSAVINA, L., Mat. Plast, 51, no.2, 2014, p.190

12. SUDARSHAN, T., SRIVATSAN, T. S., Role of phosphorus content on porosity of cast irons, Journal of Materials Science, 27 no.4, 1992, p.869.

13. ABBASI, H.R., BAZDAR, M., HALVAEE, A., Effect of phosphorus as an alloying element on microstructure and mechanical properties of pearlitic gray cast iron, Materials Science and Engineering, 444 no.12, 2007, p.314.

Manuscript received: 7.07 .2016 